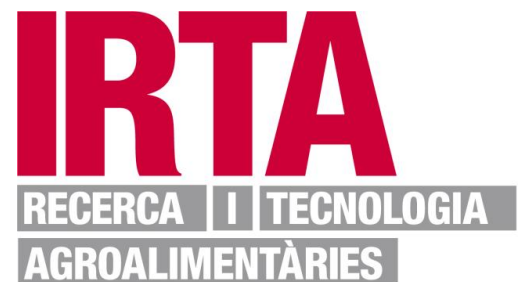

This is a post-peer-review, pre-copyedit version of an article published in Molecular Breeding. The final authenticated version is available online at: https://doi.org/10.1007/s11032-019-1040-1

Document downloaded from:

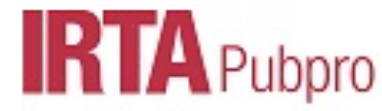

Open dgital archive 


\section{Multi-environment QTL analysis using an updated genetic map of a widely distributed Seri $\times$ Babax spring wheat population}

Caiyun Liu ${ }^{1}$, Mehdi Khodaee ${ }^{2}$, Marta S. Lopes ${ }^{3,4}$, Carolina Sansaloni ${ }^{5}$, Susanne Dreisigacker ${ }^{1}$, Sivakumar

$$
\text { Sukumaran }^{1, *}, \text { Matthew Reynolds }{ }^{1}
$$

Affiliations: ${ }^{1}$ Global Wheat Program, International Maize and Wheat Improvement Center, Km 45 Carretera México Veracruz, El Batán, Texcoco CP, México 56237; ${ }^{2}$ Department of Agronomy and Plant Breeding, College of Agriculture, Isfahan University of Technology (IUT), 84156-8311 Isfahan, Iran; ${ }^{3}$ Global Wheat Program, International Maize and Wheat Improvement Center (CIMMYT), Emex, 06511 Anakara, Turkey; ${ }^{4}$ Sustainable Field Crops Program, Institute for Food and Agricultural Research and Technology (IRTA), Lleida, Spain; ${ }^{5}$ Genetic resources program, International Maize and Wheat Improvement Center, Km 45 Carretera México Veracruz, El Batán, Texcoco CP, México 56237.

*Corresponding author: S.Sukumaran@cgiar.org

Tel: +5215541941246

\section{ORCIDS:}

Caiyun Liu: 0000-0001-7987-703X

Mehdi Khodaee:

Marta S. Lopes: 0000-0002-7698-6019

Carolina Sansaloni: 0000-0003-2675-4524

Susanne Dreisigacker: 0000-0002-3546-5989

Sivakumar Sukumaran: 0000-0003-4088-4624

Matthew Reynolds: 0000-0002-4291-4316

Keywords: 90K Wheat SNPs, DArTseq, QTL mapping, Seri $\times$ Babax, grain yield
Abbreviations:
QTL Quantitative trait locus
RIL Recombinant inbred line
SNP Single nucleotide polymorphism
PVE Phenotypic variation explained by QTL 


\section{Abstract}

2 Seri/Babax spring wheat linkage mapping population was developed to minimize the confounding effect of phenology

3 in the genetic dissection of abiotic stress traits. An existing linkage map $(<500$ markers $)$ was updated with 6,470

4 polymorphic Illumina iSelect 90K array and DArTseq SNPs to a genetic map of $5576.5 \mathrm{cM}$ with 1748 non-redundant

5 markers (1165 90K SNPs, 207 DArTseq SNPs, 183 AFLP, 111 DArT array, and 82 SSR) assigned to 31 linkage

6 groups. We conducted QTL mapping for yield and related traits phenotyped in seven major wheat growing areas from

7 Egypt, Sudan, Iran and India, and nine environments (heat, drought, heat plus drought, and yield potential) in Obregon,

8 Mexico. The current study confirmed QTLs from previous studies and identified novel QTLs. QTL analysis identified

939 (LOD: 2.5-23.6; PVE: 4.8-21.3\%), 36 (LOD: 2.5-15.4; PVE: 2.9-21.4\%), 30 (LOD: 2.5-13.1; PVE: 3.6-26.8\%),

1039 (LOD: 2.7-14.4; PVE: 2.6-15.9\%), and 22 (LOD: 2.8-4.8; PVE: 6.8-12.9\%) QTLs for grain yield, thousand-grain

11 weight, grain number, days to heading, and plant height, respectively. QTL analysis based on high-yielding and low-

12 yielding environment clusters identified 11 additional QTLs (LOD: 2.6-14.9; PVE: 2.7-19.7\%). The updated map

13 thereby provides a better genome coverage (3.5-fold) especially in D genome (4-fold), higher density (1.1-fold) and a

14 good collinearity with the IWGSC RefSeq v1.0 genome, thus increased the number of detected QTLs (5-fold)

15 compared with the earlier map. This map provides a useful genomic resource for further genetic analyses of important

16 traits in this wheat population that was widely distributed around the world. 


\section{INTRODUCTION}

Bread wheat (Triticum aestivum L.) is one of the staple food crops worldwide, contributing $\sim 28 \%$ of the global grain production and $20 \%$ of the calories and protein consumed by human (FAOstat 2018). With a predicted world population of nine billion by 2050, the demand for wheat is expected to increase (Rosegrant and Cline 2003). As the most widely cultivated crop geographically, wheat covers a large variance of climate and soil conditions. Abiotic stresses such as drought, temperature, salinity, and nutrient imbalances reduce wheat yield in many environments (Trethowan and Mujeeb-Kazi 2008). Improvement of grain yield in these target environments is the primary target of wheat research considering climate change (Reynolds et al., 2009).

Grain yield (GY) is a complex quantitative trait that is strongly influenced by interacting genetic and environmental factors (Quarrie et al. 2006). GY can be dissected into direct components: thousand-grain weight (TGW) and grain number (GN) per unit area of land. Both TGW and especially GN are quantitatively inherited and not easy to improve simultaneously through the conventional approaches due to the tradeoff between them (Yano and Sasaki 1997; Griffiths et al. 2015). Quantitative trait loci (QTL) mapping in bi-parental populations has provided an effective approach to dissect quantitative traits into component loci to study their relative effects on a specific trait of interest (Doerge 2002). A large number of QTLs for yield and yield components have been identified to date on almost all wheat chromosomes (Bennett et al. 2012; Golabadi et al. 2011; Kirigwi et al. 2007; Liu et al. 2019b; Maccaferri et al. 2008; Pinto et al. 2010; Tahmasebi et al. 2016). However, the identification of QTL for yield may be confounded by flowering time and plant height $(\mathrm{PH})$, whereby genes of major effects have been shown to mask the identification of minor effects, especially under abiotic stress where the onset of stress treatments will occur at different growth stages depending on the genotypes phenological pattern (Reynolds et al. 2009). Therefore, effects of phenology and PH may be restricted in the population to identify QTLs for major traits without the confounding effect of phenology (Lopes et al. 2013; Pinto et al. 2010; Reynolds and Tuberosa 2008).

The narrow range of $\mathrm{PH}$ and flowering time of the Seri/Babax recombinant inbred line (RIL) population makes it ideal for genetic and physiological studies. Many QTLs have been identified for agronomic and physiological traits in the Seri/Babax population under water limiting and heat stress conditions over the past decade (Lopes et al. 2013; Mathews et al. 2008; McIntyre et al. 2010; Pinto et al. 2016; Pinto et al. 2010; Tahmasebi et al. 2016). Seri/Babax population is still widely used by researchers around the world for genetic and physiological studies of different traits in various environments and some of the lines have been valuable in breeding. Genetic linkage map is 
the foundation for mapping QTLs and subsequent marker-assisted selection or map-based cloning. The existing genetic map of Seri/Babax was primarily based on 475 markers comprising SSR (Simple Sequence Repeat), AFLP

47 (Amplified Fragment Length Polymorphism), and DArT (Diversity Arrays Technology) markers (Lopes et al. 2013).

With the rapid development of new genotyping technologies, numerous molecular makers for wheat are available now. Therefore, a new linkage map is necessary for researchers to compare their results with peers. By genotyping the Seri/Babax population with the wheat 90K Illumina iSelect array and DArTseq platform, the objectives of the study was 1) to update the genetic linkage map of the Seri/Babax population by integrating $90 \mathrm{~K}$ and DArTseq markers to the existing linkage map; 2) to identify QTLs for yield and yield-related traits with phenotypic data from multiple environments, combining studies not used earlier and from earlier published data; and 3) to compare the properties of the updated genetic map with the existing linkage map.

\section{MATERIALS AND METHODS}

\section{Wheat population and phenotyping}

The Seri/Babax population comprising 156 RILs was derived from a reciprocal cross between two elite spring bread wheat, Seri M82 (a released line from the "Veery" cross, KVZ/BUHO// KAL/BB) and Babax (a line derived from the cross "Babax", BOW/NAC//VEE/3/BJY/COC) (Olivares-Villegas et al. 2007). Seri M82 carries the 1BL.1RS translocation and was characterized by moderate tolerance to drought conditions and high yield potential. Babax is without the 1BL.1RS translocation, and is highly tolerant to severe drought (Mathews et al. 2008). Seri M82 and Babax both have the same photoperiod-insensitive allele at $P p d-D 1$, and spring-type alleles for vernalization ( $V r n-B 1$ and $V r n-D 1$ ) loci (Pinto et al. 2010). Hence, this population is characterized by its narrow range of plant height and flowering time (ca. $17 \mathrm{~cm}, 10-15$ days across environments as reported by Lopes et al. (2013)), and is ideal for genetic mapping and physiological studies. The phenotyping was conducted in eight major wheat growing regions from five countries around the world (Fig. 1a), including ten environments (Darab in Iran, Sohag in Egypt, Dongola and Wad Medani in Sudan, Ludhiana and Karnal in India, and yield potential, drought stress, heat stress, and heat plus drought stress in Obregon, Mexico in 2008-2009) reported in an earlier study (Lopes et al. 2013), and six new environments (one from Shandaweel, Egypt in 2008-2009, and five from different stresses in Obregon, Mexico in 2004-2005 and

71 2005-2006). The sowing and harvest date, temperature, precipitation, total amount of water applied by irrigation, relative humidity, and evapotranspiration during the growing season were reported in an earlier study (Lopes et al. 
74 Obregon, where the environments were designated as yield potential, drought stress, heat stress, and heat plus drought 75 stress. Yield potential (YP) was applied by normal sowing (late November) with optimum irrigation (total water supply $76>700 \mathrm{~mm}$ ); drought stress (D) was applied by normal planting (late November) with significantly reduced irrigation

77 (total water supply $<300 \mathrm{~mm}$ ); heat stress $(\mathrm{H})$ was applied by late sowing (late February) with supplementary 78 irrigation (total water supply $>700 \mathrm{~mm}$ ) to avoid the effect of drought; and the combined heat plus drought stress 79 (HD) was applied by delayed planting date (late February) with reduced irrigation (total water supply $<400 \mathrm{~mm}$ ). By late sowing, the average maximum temperature during wheat growing cycle was above $32^{\circ} \mathrm{C}$, almost $8^{\circ} \mathrm{C}$ higher than

81 that in normal sowing cycles (Liu et al. 2019b; Pinto et al. 2010), a typical method for applying heat stress in Obregon 82 that has been demonstrated to be successful in generating germplasm for heat stress environments such as ME5 83 (Reynolds et al. 1994). The experimental design was randomized lattice with two replications. Seeds were sown on raised beds of $2 \mathrm{~m}$ length with 2 rows $(25 \mathrm{~cm}$ between rows) and $80 \mathrm{~cm}$ between the beds, with seed rates of 120 $\mathrm{kg} / \mathrm{ha}$. Five agronomic traits were measured: grain yield $\left(\mathrm{GY} ; \mathrm{t} \mathrm{ha}^{-1}\right)$, thousand-grain weight (TGW, g), grain number $\left(\mathrm{GN}\right.$; estimated as: $\left.\mathrm{GY}\left(\mathrm{tha}^{-1}\right) / \mathrm{TGW}(\mathrm{g}) \times 100 \times 1000\right)$, days to heading $(\mathrm{DTH}$, i.e. the number of days from emergence when $50 \%$ of the spike were emerged), and plant height $(\mathrm{PH}, \mathrm{cm}$ from the soil surface to the tip of the spike without awns).

\section{Phenotypic data analysis}

91 The adjusted means for each genotype in individual environment were calculated using the MIXED procedure in SAS 92 as described by Lopes et al. (2013). Cluster of environments based on yield performance was generated using the 93 “cluster" package in R (Maechler 2019). where $\sigma_{g}^{2}$ and $\sigma_{\mathrm{e}}^{2}$ were genotype and error variance, and $r$ was the number of replications.

$$
H^{2}=\frac{\sigma_{g}^{2}}{\sigma_{g}^{2}+\sigma_{e}^{2} / r}
$$

For the combined analysis of high-yielding and low-yielding clusters, the $H^{2}$ was estimated as:

$$
H^{2}=\frac{\sigma_{g}^{2}}{\sigma_{g}^{2}+\sigma_{g e}^{2} / l+\sigma_{e}^{2} / r l}
$$

where $\sigma_{\mathrm{ge}}^{2}$ was the genotype by environment interaction variance, and $l$ was the number of environment. 


\section{Genotyping, map construction and QTL mapping}

A genetic map with 475 markers (120 SSR, 211 AFLP, and 144 DArT) distributed over 29 linkage groups (LGs) had been previously constructed for this population (Lopes et al. 2013). Recently, the Seri/Babax RIL population was genotyped with the wheat $90 \mathrm{~K}$ Illumina iSelect array and DArTseq platform (data available at https://data.cimmyt.org/dataset.xhtml?persistentId=hdl:11529/10548196). After quality control (removing markers with minor allele frequency $<5 \%$, missing data $>15 \%$, and segregation distortion $p<0.05$ ), an additional 5386- 90K SNP and 609 DArTseq SNP -markers were added to construct the linkage map. A new genetic map was constructed using QTL IciMapping v4.1 (Meng et al. 2015), which combined the map with the previous 475 markers and the new SNP markers. The 90K and DArTseq markers were assigned to chromosomes based on the IWGSC RefSeq v1.0 genome. Within each chromosome, genetic distance was determined using the Kosambi mapping function (Kosambi 2016). Chromosomes were split into LGs and reordered when the gap between two adjacent markers were $>50 \mathrm{cM}$. interval mapping of additive (ICIM-ADD) function was selected as mapping method to detect additive QTL. The LOD threshold for QTL detection was determined by using 1000 permutations at $P<0.05$. Putative QTLs were declared using a LOD of 2.5. QTLs detected across environments were considered the same if the distance between the peak positions was less than $10 \mathrm{cM}$. Stable QTLs were declared when QTLs were identified in at least two environments.

\section{RESULTS}

\section{Phenotypic variations across environments}

121 The phenotypic traits of the Seri/Babax RIL population showed a wide range of variation across environments 122 (Supplementary Table 1). The highest mean GY was found in Sohag $\left(7.5 \mathrm{t} \mathrm{ha}^{-1}\right)$ and Shandaweel $\left(7.5 \mathrm{t} \mathrm{ha}^{-1}, H^{2}=\right.$ $0.45)$ in Egypt, while the lowest mean GY was found in Obregon under heat stress in $2006\left(1.1 \mathrm{t} \mathrm{ha}^{-1}, H^{2}=0.79\right.$; Table

1). Cluster analysis of the 16 environments for GY generated two main groups: the high-yielding group ( $>5.5 \mathrm{tha}^{-1}$, $H^{2}=0.35$ ) comprising Sohag and Shandaweel in Egypt, Ludhiana in India, Dongola in Sudan, and two yield potential 
(Fig. 1b). The correlation analysis for GY was consistent with the results of cluster analysis, with Sohag and Shandaweel in Egypt showing the highest correlation. Most of the environments showed positive correlations with each other, while Wad Medani was negatively correlated with Obregon drought stress in 2004-2005 and 2005-2006 growing seasons (Fig. 1c).

Similar to GY, the highest average TGW $\left(45.4 \mathrm{~g}, H^{2}=0.54\right)$ was observed in Sohag and Shandaweel in Egypt, while the lowest TGW (26.6 g, $\left.H^{2}=0.78\right)$ was found in Obregon heat plus drought stress environment (Table 1). The highest GN $\left(18558, H^{2}=0.88\right)$ was found in Ludhiana, India with a large range, and the lowest GN $\left(3405, H^{2}\right.$ $=0.48$ ) was observed in Obregon drought stress in 2005-2006. The phenology range was 6 to 18 days across environments. In Darab, Iran, the Seri/Babax population had the longest time-112 days-for days to heading; while in Obregon heat plus drought environment, the mean days to heading was 53 days. The Seri/Babax population had the highest PH in Sohag and Shandaweel $(107.5 \mathrm{~cm})$, and lowest mean PH $(71 \mathrm{~cm})$ for the population in Obregon heat plus drought condition. The largest and smallest range for $\mathrm{PH}$ was observed in Wad Medani (a range of $40 \mathrm{~cm}$ ) and Obregon heat stress in 2009 (a range of $15.5 \mathrm{~cm}$ ), respectively.

\section{Trait associations across environments}

Across the 16 environments, GY was significantly positively correlated with TGW ( $r$ range: $0.29-0.77)$, GN $(0.48$ 0.94), DTH (0.32-0.69), and PH (0.24-0.73) in most of the environments with a few exceptions: GY was weakly negatively correlated with TGW under Obregon heat stress $(2005,2006 ; r=-0.03)$, with GN under Obregon drought stress (2005-2006; $r=-0.03)$, and with DTH in Shandaweel of Egypt $(r=-0.13$; Supplementary Fig. 1). TGW and GN was positively correlated with each other in 10 environments ( $r$ range: 0.19-0.55) except in Shandaweel of Egypt $(r=-0.63)$, Obregon yield potential (2008-2009; $r=-0.62)$, drought $(2005-2006 ; r=-0.36)$, and heat $(2005,2006 ; r$ ranges from -0.32 to -0.46 ) conditions, where negative correlations were observed. TGW was positively correlated with DTH ( $r$ range: $0.87-0.96)$ except in Shandaweel of Egypt $(r=-0.33)$. TGW was positively correlated with PH $(r$ range: $0.90-0.97)$ except in Darab, Iran. GN was positively correlated with DTH ( $r$ range: $0.14-0.61)$ and PH ( $r$ range: 0.90-0.97) in all environments.

\section{Genetic linkage map construction}


We used 6470 markers comprising SSR (120), AFLP (211), DArT (144), 90K SNP (5386), and DArTseq SNP (609) markers to construct the genetic map. Discarding redundant markers at the same loci, the final genetic map was 5576.5 cM with 1748 markers (82 SSR, 183 AFLP, 111 DArT, 1165 90K SNPs, and 207 DArTseq SNPs) arranged to 31 LGs (Fig. 2, Supplementary Table 2). The total length of the updated map increased 3.5 folds than that of the previous one Lopes et al. (2013). The A, B and D genomes harbored 768 (44\%), 648 (37\%) and 332 (19\%) markers with a total length of 1959.5, 1961.9, and $1655.1 \mathrm{cM}$, respectively. The current map provided a better coverage of all the 21 chromosomes than the previous one, in which only $11 \%$ of markers were distributed on D genome and no markers were assigned to 3D. On the updated map, the longest $\mathrm{LG}$ was $4 \mathrm{~A}(352.5 \mathrm{cM})$, followed by $6 \mathrm{~A}(351.6 \mathrm{cM})$ and $1 \mathrm{D}$ $(350.6 \mathrm{cM})$. The shortest $\mathrm{LG}$ was 7Dc $(4.7 \mathrm{cM})$, followed by $3 \mathrm{Ab}(7.2 \mathrm{cM})$. Marker density was lowest in 3D $(16.2 \mathrm{cM}$ per marker), followed by $1 \mathrm{Ba}(14.1 \mathrm{cM}$ per marker), and highest in $7 \mathrm{Dc}(0.9 \mathrm{cM}$ per marker), followed by $1 \mathrm{~A}(1.6 \mathrm{cM}$ per marker, Table 2). We obtained the physical position of 1059 mapped markers on the linkage map and projected our linkage map to the IWGSC RefSeq v1.0 genome. Results showed there was a good collinearity between the updated genetic map and the physical map (Fig. 3).

Of the 1748 mapped markers, significant segregation distortion (CHITEST, $p<0.001)$ was found in $68(4 \%)$ markers including 28 DArT, 25 AFLP, 9 SSR, and 6 DArTseq markers. Fifty-eight and ten markers showed distortion with alleles biased towards parent Babax and Seri, respectively. The markers that showed segregation distortion in favor of the Babax parent were mainly distributed on $1 \mathrm{Bb}$ (35.6-104.9 cM, 43 markers), while those in favor of the Seri parent were mainly assigned to $3 \mathrm{Aa}(142-153 \mathrm{cM}, 8$ markers).

Clusters of markers from the same marker type on the map were frequently observed (Fig. 2). Of the 1748 mapped markers, 1270 markers (73\%) were adjoined with markers from the same type. Marker intervals with a distance $<0.5 \mathrm{cM}$ between two adjacent markers from the same type were observed in 326, 26, 6, 4, and 1 intervals for 90K, DArTseq, AFLP, DArT, and SSR markers, accounting for 34\%, 29\%, $8 \%, 15 \%$, and $7 \%$ of their total intervals (Supplementary Fig. 2). The frequency of clustering was primarily related to the number of markers from different types.

We also built a linkage map only using the 90K SNPs to a map length of $5333 \mathrm{cM}$ with 1222 non-redundant 90K markers. While there were many large gaps on the map with 90K SNPs (Supplementary Table 3), indicating the necessity to include different types of markers. As was shown in Fig. 2, DArTseq, DArT, SSR, AFLP markers could cover most of the large gaps. 


\section{QTLs identified in individual environments}

185 A total of 166 QTLs with LOD scores from 2.5 to 23.7 were identified for GY, TGW, GN, DTH, and PH in the 16 environments with the updated genetic map (Supplementary Table 4). The number of QTLs was higher than the earlier map where 31 QTL were detected for the same traits (Table 2). The largest number of QTLs was identified on chromosome 4A (23), followed by 7Da (22). No QTL was identified on 1Ba, 2Da, 3Ab, 3Ba, 5Db, 7Bb, 7Db, and 7Dc (Supplementary Fig. 3).

QTLs for GY were identified on chromosome 1A, 1Bb, 1D, 2Db, 3Aa, 3Bb, 4A, 4B, 5A, 5Da, 6A, 6B, 6Da,

7A, and 7Da (LOD: 2.6-23.6; PVE: 4.8-21.3\%; Supplementary Table 4, Supplementary Fig. 3). Seven stable QTLs on chromosomes 3Aa (128-134 cM), 3Bb (228-232 cM), 4A (268 cM, 280-286 cM, 304-308 cM), 6B (206-208 cM), and 7Da $(124 \mathrm{cM})$ were detected in at least two environments (Table 3). The stable QTL on chromosome 4A (304308 cM, Fig. 4) was detected across the yield potential (2005-2006, 2008-2009), drought (2008-2009), and heat plus drought (2009) conditions in Obregon, Mexico. QTLs for TGW were identified on chromosome 1A, 1D, 2B, 3Bb, 4A, 4B, 5A, 5B, 5Da, 6A, 6B, 7A, 7Ba, and 7Da (LOD: 3-15.4; PVE: 3-21.4\%). Six stable QTLs on chromosomes 2B (44-46 cM), 3Bb (44-48 cM), 6A (218 cM), 7Ba (26-32 cM), and 7Da (108-116 cM, $124 \mathrm{cM})$ were identified

(Table 3). The QTL on chromosome 7Da (108-116 cM) was detected in six environments across Karnal in India, Darab in Iran, and Obregon yield potential (2005-2006, 2008-2009) and drought (2005-2006, 2008-2009) conditions. QTLs for GN were identified on chromosome 1A, 1Bb, 1D, 2A, 2B, 3Aa, 3Bb, 4A, 4B, 4Db, 5A, 6B, 6Db,

7A, and 7Da (LOD: 2.5-13.1; PVE: 3.6-26.9\%). Three stable QTLs were identified on chromosomes 1Bb (72-80 cM),

4A (308 cM, Fig. 4), and 6B (214 cM) in Obregon, Mexico (Table 3), of which the QTL on 6B (214 cM) was a heat adaptive QTL. QTLs for DTH were located on chromosome 1Bb, 1D, 2A, 2B, 3D, 4B, 4Da, 5A, 5Da, 6B, 6Db, 7A, 7Ba, and 7Da (LOD: 2.7-14.4; PVE: 2.6-15.9\%). Eight stable QTLs were identified on chromosome 2A (158-160 cM), 4B (70 cM, $186 \mathrm{cM}), 5 \mathrm{Da}(38 \mathrm{cM}), 6 \mathrm{~B}$ (206 cM), 7Ba (20-22 cM), and 7Da (110-112 cM, 120-124 cM) across environments. QTLs for PH were identified on chromosome 1D, 2B, 3Aa, 4A, 4B, 4Db, 5A, 6A, 7Ba, and 7Da (LOD: 2.8-4.8; PVE: 6.9-12.9\%). Four stable QTLs on chromosomes 2B (84 cM), 3Aa (166 cM), 4A (268-272 cM), and 4B

\section{QTLs identified for high-yielding and low-yielding clusters}


A QTL analysis based on the high- and low-yielding clusters identified 32 QTLs (LOD range: 2.6-14.9, PVE: 2.719.7\%) for GY, TGW, GN, DTH, and PH, of which 11 QTLs were new and absent in individual environments (Supplementary Table 5). Six QTLs on chromosomes 1A, 1Bb, 2B, 4A, and 4Db were specific for high-yielding cluster, 16 QTLs on chromosomes 1A, 1Bb, 4A, 4B, 4D, 6B, 7A, 7Ba, and 7Da were specific for low-yielding cluster, and five QTLs on chromosomes 1D, 3Aa, 7Ba, and 7Da were common between the two clusters (Fig. 5).

QTLs for GY were found on chromosomes $1 \mathrm{Bb}(28 \mathrm{cM}$, new) and 4A (26 cM) in high-yielding cluster; on 4A (4 cM, $282 \mathrm{cM})$ and 4B (186 cM) in low-yielding cluster; and the common QTL was located on 1D (26 cM, new). For TGW, the QTLs for low-yielding cluster were identified on chromosomes $1 \mathrm{~A}(242 \mathrm{cM})$ and $7 \mathrm{Ba}(26 \mathrm{cM})$, and the common QTL was identified on 7Da (114-116 cM). For GN, QTLs were located on chromosomes 1A (86 cM, new) and 4A (2 cM, new) in high-yielding cluster, and on 1Bb (74 cM), 4A (158 cM, new; $268 \mathrm{cM}), 4 \mathrm{Db}(90 \mathrm{cM}), 6 \mathrm{~B}(218$ $\mathrm{cM})$, and 7A (60 cM, new) in low-yielding cluster. For DTH, common QTLs were identified on 1D (30-32 cM) and 7Ba (20 cM); high-yielding cluster specific QTL was located on chromosome 4Db (102 cM, new); and low-yielding cluster specific QTLs were located on chromosomes 4B (70 cM), 6B (206 cM), 7A (264 cM), 7Ba $(20 \mathrm{cM})$, and 7Da (114 cM). For PH, QTL in high and low yield cluster was identified on chromosomes 2B (64 cM, new) and 7Ba (130 $\mathrm{cM})$, respectively. The common QTL for PH in both clusters was located on chromosome 3Aa (122 cM, new).

\section{Pleiotropic QTL}

Pleiotropic QTLs were observed in this study (Fig. 6). Among the 21 QTL hotspots for multiple traits, nine were independent from DTH and/or PH QTL. Co-location of QTL for GY, TGW, and GN was on chromosome 1D at 194$198 \mathrm{cM}$, where the favorable allele for GY and TGW was contributed by Babax, while for GN was from Seri. Colocations of QTLs for GY and TGW were observed on chromosomes 3Bb (228-236 cM) where the favorable allele was contributed by Babax, and on chromosome 5A $(26 \mathrm{cM})$ where the favorable allele was contributed by Seri. Colocation of QTLs for GY and GN were on chromosomes 1A $(120 \mathrm{cM})$ where the favorable allele was from Seri, and on chromosome 1Bb (68-92 cM), 4A (56-62 cM, 280-286 cM, 304-308 cM), and 4B (32 cM) where favorable alleles were contributed by Babax.

\section{DISCUSSION}


The rapid advances in genotyping technologies exponentially increase the number of markers available for genetic studies. Genetic maps are very useful tools in the identification of molecular markers closely linked to QTLs of interest, isolation of genes via map-based cloning, comparative mapping, and genome organization studies (Varshney et al. 2007). In the present study, with the addition of the 90K SNP and DArTseq SNP markers, the number of mapped markers (1748) on the genetic map of Seri/Babax increased 3.5 folds compared with the previous map of 475 markers (Lopes et al. 2013). The final size of the linkage map was $5576.5 \mathrm{cM}$, almost 3.5-fold the length of the previous one (Lopes et al. 2013). The current map provides a better coverage of the 21 chromosomes of wheat than the previous one where linkage group 3D was absent (Lopes et al. 2013; McIntyre et al. 2010). Around 19\% of markers were assigned to D genome, which was higher than the earlier D genome with $11 \%$ of markers. Though the updated map showed a better genome coverage, gaps with a distance $>50 \mathrm{cM}$ still remained on chromosome 1B, 2D, 3A, 3B, 4D, 5D, 6D, 7B, and 7D, where small LGs were generated. Gaps of distances $>20 \mathrm{cM}$ were observed almost on all LGs and need to be filled with more markers for the non-centromeric regions. Of the 1748 mapped markers, 11 markers were assigned to $3 \mathrm{D}$, confirming the difficulty in identifying polymorphic markers for 3D, perhaps due to the large common regions of 3D between the Seri and Babax (McIntyre et al. 2010). In addition, the lower frequency of polymorphic markers in $\mathrm{D}$ genome compared with $\mathrm{AB}$ genome in wheat makes it difficult to have a good coverage of D genome (Allen et al. 2011; Chao et al. 2009). The final map comprised of markers from AFLP, SSR, DArT, 90K, and DArTseq, and clustering of markers from the same marker platform on the map were frequently observed. The frequency of marker clustering was primarily related to the number of markers from different types. For example, clustering of $90 \mathrm{~K}$ markers was more frequent than other types, which was not surprising since the number of $90 \mathrm{~K}$ markers were more abundant than others. The occurrence of clusters are very common when different kinds of markers are integrated into a single linkage map (Peleg et al. 2008; Semagn et al. 2006). Overall, the updated genetic map provided a higher density (1.1-fold) map with more markers (3.5-fold) and a good collinearity with the IWGSC RefSeq v1.0 genome, representing a step forward in mapping analysis and also in comparing QTLs with other studies using 90K genetic map.

With the updated integrated genetic map, the number of identified QTLs was increased by five-fold compared with the previous study (Lopes et al. 2013) and 25 QTLs were common between the two studies (Supplementary table 6). Since the Seri/Babax population was widely used for QTL studies (Mathews et al. 2008; McIntyre et al. 2010; Pinto et al. 2016; Pinto et al. 2010; Tahmasebi et al. 2016), we managed to locate all the reported QTLs on the 
updated map and found that the QTLs were clustered on several big chromosome regions (Supplementary table 6).

267 For example, on chromosome $1 \mathrm{Bb}$ at $70-105 \mathrm{cM}$, there was a big cluster of QTLs for GY, TGW, GN, DTA, PH,

NDVI, CT, SPAD, harvest index, rate of senescence, and percentage of greenness lost. On chromosome 2B (24-84 cM), QTLs for GY, TGW, GN, DTH, PH, CT, maturity, grains per spike, leaf rolling, and spikelet compactness were co-located. On chromosome 4A at 265-300 cM, QTLs for GY, GN, and PH in the present study were co-located with QTLs for CT, NDVI, grain-filling rate, and water-soluble carbohydrates. On chromosome 5A (69-139 cM), QTLs for

272 GY, GN, DTH, PH, spikelet per spike, spikelet compactness, flowering time, maturity, and leaf rolling were clustered.

On chromosome 6B at 182-216 cM, QTLs for GY, TGW, GN, DTH, grain-filling rate, spikelet per spike, spikelet compactness, grains per spike, and percentage of greenness lost at mid grain-filling stage were frequently identified. Pinto et al. (2010) reported six common QTLs for drought and heat stress on chromosome 1B-a, 2B-a, 3B-b, 4A-a, 4B-b, and 7A-a in the Seri/Babax population in Obregon, Mexico environments, while in the present study, the QTL on chromosome 1B-a can be detected in Obregon heat stress in 2006 (71-75 cM on 1Bb in the present study); the QTL on chromosome 2B-a was detected in Wad Medani, Dongola, Darab, and Obregon heat stress in 2009 (39-47 cM on 2B); the QTL on chromosome 3B-b was detected in Obregon yield potential (2005-2006), drought (2004-2005), and heat (2006) conditions (219-235 cM on 3Bb); the QTL on chromosome 4A-a was detected across Obregon heat stress (2006, 2009), Ludhiana, Shandaweel, and Sohag (265-269 cM on 4A); the QTL on chromosome 4B-b was identified in Obregon heat plus drought stress (2009), Darab, Dongola, and Ludhiana (189-195 cM on 4B), the QTL on 7A-a was detected in Wad Medani and Karnal (265-267 cM on 7A). These results suggested that the experiments and breeding conducted in drought and heat stress environments in Obregon, Mexico could be used to predict the performance of the germplasm in other parts of the world. Reynolds et al. (1994) also reported that the typical heat stress in Obregon was demonstrated to be successful in generating germplasm for heat stressed environments such as ME5 comprising India and Sudan (Hodson and White 2007; Rajaram et al. 1993).

Typically, there is a trade-off between grain weight and grain number, making it difficult to improve yield through increasing grain weight and grain number at the same time (Griffiths et al. 2015; Sukumaran et al. 2018a;

290 Sukumaran et al. 2018b). However, in the present study, TGW and GN were observed to be positively correlated, and 291 both TGW and GN were positively correlated with GY in most environments. Several QTLs co-located for GY and 292 GN were found on chromosome 1A (120 cM), 1Bb (68-92 cM), 4A (56-62, 280-286, 304-308 cM), and 4B (32 cM), where QTLs for GY and GN shared the favorable allele from the same parent. QTLs co-located for GY and TGW 
were on chromosome $3 \mathrm{Bb}(228-236 \mathrm{cM})$ and $5 \mathrm{~A}(26 \mathrm{cM})$, where the same parent contributed the favorable allele for both GY and TGW. Among the QTLs co-located for TGW and GN, most of the favorable alleles for TGW and GN were contributed by different parents, while the QTL on chromosome 6B $(194-200 \mathrm{cM})$ shared the favorable allele from the same parent for TGW and GN, indicating it is possible to improve yield through TGW QTL complemented by adding correlated GN QTL (Groos et al. 2003).

The stable heat adaptive QTL on chromosome 1D (84 cM) for GY could be projected to 484-493 Mb on the IWGSC RefSeq v1.0 genome, where genes were located for disease resistance, heat shock family protein, and early flowering. The QTL on chromosome $2 \mathrm{Db}(110 \mathrm{cM})$ for GY was previously identified for photochemical reflectance index (PRI) in a CIMMYT spring wheat population (WAMI) under yield potential condition (Liu et al. 2019a). The QTL on chromosome 3Bb (228-236 cM) for GY and TGW was very close to a locus associated with multiple traits (GY, maturity, and chlorophyll content at vegetative state) in the temperate irrigated environments in spring wheat (Sukumaran et al. 2015). The QTL on chromosome 4A (308 cM) for GY and GN could be mapped to 531-535 Mb in physical map, which contains 34 genes including heat-shock protein genes. The TGW QTL on chromosome 7Ba (26$32 \mathrm{cM}$ ) was located at 3.7-5.9 Mb on the physical map, which harbored 33 genes. The GN QTL on chromosome 1A $(86 \mathrm{cM})$ was associated with ground cover in winter wheat (Gao et al. 2016). The GN QTL on chromosome 6Db (8 cM) was co-located with a QTL for DTH in a synthetic derived RIL population (Liu et al. 2019b).

The Seri/Babax population was initially developed in Obregon, Mexico, so the lowest range of DTH (8 days) and PH $(15-23 \mathrm{~cm})$ was observed in the Obregon environments in this study. When grown in international trials, longer DTH and higher PH with a wider range were observed in most environments. For DTH, the QTL on chromosome 4Da was previously reported for maturity in spring wheat (Sukumaran et al. 2015). The QTL on chromosome 5D (38 cM) was located at a distance (about $60 \mathrm{Mb}$ ) from the Vrn-D4 locus (Yoshida et al. 2010). The stable QTL for DTH on 315 chromosome 7Ba (20-22 cM) was co-located with a previously reported QTL for kernel number per spike (Gao et al. 316 2015). Projecting this QTL to the physical map, it was located at the Vrn-B3 locus (Yan et al. 2006), which could 317 accelerate flowering and bypass the vernalization requirement of its dominant allele if present. This QTL was contributed by the parent Seri, and has never been reported before by other studies using Seri/Babax. The other QTLs for DTH are most likely to be associated with earliness per se genes that act independently of environmental signals, and are usually responsible for fine-tuning flowering time (Flood and Halloran 1984). For PH, the locus on chromosome 4B (192-194 cM) was associated with GY in a CIMMYT spring wheat panel (Sukumaran et al. 2013). 
This locus can be projected to $3.5-4.7 \mathrm{Mb}$ on the physical map, which was very close to the Rht-Bl gene (Pearce et al. 2011). The PH QTL on chromosome 5A (72 cM) was also associated with Cephalosporium stripe resistance in wheat (Quincke et al. 2011).

This study updated the genetic map of the widely used Seri/Babax RIL population with the 90K and DArTseq SNPs. The updated genetic map has a good genome coverage, higher marker density, and a good collinearity with the physical map, and increased the number of QTLs compared with the earlier studies. A larger number of QTLs were identified with this genetic map across various environments, and some of them were stable in different environments. QTLs that are unique to the current study, verify the importance of an updated genetic map for QTL detection. This updated genetic map is expected to serve as a platform for further genetic analyses of important quantitative traits, map-based cloning, and marker-assisted selection studies using Seri/Babax RIL population.

\section{AUTHOR CONTRIBUTIONS}

SS designed the current study, ML and MR provided the phenotypic data, CS contributed with the explanation of DArTseq data, SD and MR genotyped the population, CL, SM and SS created the genetic maps and analyzed the data, CL and SS wrote the manuscript. All authors reviewed and accepted the contents.

\section{ACKNOWLEDGEMENTS}

This work was implemented by CIMMYT as part of IWYP-HUB, made possible by the generous support of International Wheat Yield Partnership (IWYP). Any opinions, findings, conclusion, or recommendations expressed in this publication are those of the authors and do not necessarily reflect the view of donors. We also acknowledge Dr. Marc Ellis for providing DArTseq data for the population. Thanks are due to the staff at Wheat Physiology lab at CENEB, Cd. Obregon, México.

\section{CONFLICT Of INTEREST}

The authors declare no conflict of interest.

\section{Reference}


Allen AM, Barker GL, Berry ST, Coghill JA, Gwilliam R, Kirby S, Robinson P, Brenchley RC, D’Amore R, McKenzie N (2011) Transcript-specific, single-nucleotide polymorphism discovery and linkage analysis in hexaploid bread wheat (Triticum aestivum L.). Plant biotechnology journal 9 (9):1086-1099

Bennett D, Reynolds M, Mullan D, Izanloo A, Kuchel H, Langridge P, Schnurbusch T (2012) Detection of two major grain yield QTL in bread wheat (Triticum aestivum L.) under heat, drought and high yield potential environments. Theoretical and Applied Genetics 125 (7):1473-1485

Chao S, Zhang W, Akhunov E, Sherman J, Ma Y, Luo M-C, Dubcovsky J (2009) Analysis of gene-derived SNP marker polymorphism in US wheat (Triticum aestivum L.) cultivars. Molecular Breeding 23 (1):23-33

Doerge RW (2002) Multifactorial genetics: Mapping and analysis of quantitative trait loci in experimental populations. Nature Reviews Genetics 3 (1):43

FAOstat (2018) The Statistics Division, Food and Agriculture Organization of the United Nations.

Flood RG, Halloran GM (1984) Basic Development Rate in Spring Wheat1. Agronomy Journal 76 (2):260-264. doi:10.2134/agronj1984.00021962007600020021x

Gao F, Liu J, Yang L, Wu X, Xiao Y, Xia X, He Z (2016) Genome-wide linkage mapping of QTL for physiological traits in a Chinese wheat population using the 90K SNP array. Euphytica 209 (3):789-804. doi:10.1007/s10681-016-1682-6

Gao F, Wen W, Liu J, Rasheed A, Yin G, Xia X, Wu X, He Z (2015) Genome-wide linkage mapping of QTL for yield components, plant height and yield-related physiological traits in the Chinese wheat cross Zhou 8425B/Chinese Spring. Frontiers in Plant Science 6:1099

Golabadi M, Arzani A, Maibody SM, Tabatabaei BS, Mohammadi S (2011) Identification of microsatellite markers linked with yield components under drought stress at terminal growth stages in durum wheat. Euphytica 177 (2):207-221

Griffiths S, Wingen L, Pietragalla J, Garcia G, Hasan A, Miralles D, Calderini DF, Ankleshwaria JB, Waite ML, Simmonds J (2015) Genetic dissection of grain size and grain number trade-offs in CIMMYT wheat germplasm. PloS one 10 (3):e0118847

Groos C, Robert N, Bervas E, Charmet G (2003) Genetic analysis of grain protein-content, grain yield and thousandkernel weight in bread wheat. Theoretical and Applied Genetics 106 (6):1032-1040 
Hodson D, White J (2007) Use of spatial analyses for global characterization of wheat-based production systems. Journal of Agricultural Science Cambridge 145 (1):115-125

Kirigwi F, Van Ginkel M, Brown-Guedira G, Gill B, Paulsen GM, Fritz A (2007) Markers associated with a QTL for grain yield in wheat under drought. Molecular Breeding 20 (4):401-413

Kosambi DD (2016) The estimation of map distances from recombination values. In: DD Kosambi. Springer, pp $125-130$

Liu C, Pinto F, Cossani CM, Sukumaran S, Reynolds PM (2019a) Spectral reflectance indices as proxies for yield potential and heat stress tolerance in spring wheat: heritability estimates and marker-trait associations. Frontiers of Agricultural Science and Engineering. doi:10.15302/j-fase-2019269

Liu C, Sukumaran S, Claverie E, Sansaloni C, Dreisigacker S, Reynolds M (2019b) Genetic dissection of heat and drought stress QTLs in phenology-controlled synthetic-derived recombinant inbred lines in spring wheat. Molecular Breeding 39 (3):34

Lopes MS, Reynolds MP, McIntyre CL, Mathews KL, Kamali MJ, Mossad M, Feltaous Y, Tahir IS, Chatrath R, Ogbonnaya F (2013) QTL for yield and associated traits in the Seri/Babax population grown across several environments in Mexico, in the West Asia, North Africa, and South Asia regions. Theoretical and applied genetics $126(4): 971-984$

Maccaferri M, Sanguineti MC, Corneti S, Ortega JLA, Salem MB, Bort J, DeAmbrogio E, del Moral LFG, Demontis A, El-Ahmed A (2008) Quantitative trait loci for grain yield and adaptation of durum wheat (Triticum durum Desf.) across a wide range of water availability. Genetics 178 (1):489-511

Maechler M (2019) Finding Groups in Data": Cluster Analysis Extended Rousseeuw et. R Packag version 206

Mathews KL, Malosetti M, Chapman S, McIntyre L, Reynolds M, Shorter R, van Eeuwijk F (2008) Multienvironment QTL mixed models for drought stress adaptation in wheat. Theoretical and Applied Genetics 117 (7):1077-1091. doi:10.1007/s00122-008-0846-8

McIntyre CL, Mathews KL, Rattey A, Chapman SC, Drenth J, Ghaderi M, Reynolds M, Shorter R (2010) Molecular detection of genomic regions associated with grain yield and yield-related components in an elite bread wheat cross evaluated under irrigated and rainfed conditions. Theoretical and Applied Genetics 120 (3):527-541. doi:10.1007/s00122-009-1173-4 
Meng L, Li H, Zhang L, Wang J (2015) QTL IciMapping: Integrated software for genetic linkage map construction and quantitative trait locus mapping in biparental populations. The Crop Journal 3 (3):269-283. doi:10.1016/j.cj.2015.01.001

Olivares-Villegas JJ, Reynolds MP, McDonald GK (2007) Drought-adaptive attributes in the Seri/Babax hexaploid wheat population. Functional Plant Biology 34 (3):189-203

Pearce S, Saville R, Vaughan SP, Chandler PM, Wilhelm EP, Sparks CA, Al-Kaff N, Korolev A, Boulton MI, Phillips AL, Hedden P, Nicholson P, Thomas SG (2011) Molecular Characterization of $<$ em $>$ Rht $-1</$ em $>$ Dwarfing Genes in Hexaploid Wheat. Plant Physiology 157 (4):1820-1831. doi:10.1104/pp.111.183657

Peleg Z, Saranga Y, Suprunova T, Ronin Y, Röder MS, Kilian A, Korol AB, Fahima T (2008) High-density genetic map of durum wheat $\times$ wild emmer wheat based on SSR and DArT markers. Theoretical and Applied Genetics $117(1): 103$

Pinto RS, Lopes MS, Collins NC, Reynolds MP (2016) Modelling and genetic dissection of staygreen under heat stress. Theor Appl Genet 129 (11):2055-2074. doi:10.1007/s00122-016-2757-4

Pinto RS, Reynolds MP, Mathews KL, McIntyre CL, Olivares-Villegas J-J, Chapman SC (2010) Heat and drought adaptive QTL in a wheat population designed to minimize confounding agronomic effects. Theoretical and Applied Genetics 121 (6):1001-1021

Quarrie S, Pekic Quarrie S, Radosevic R, Rancic D, Kaminska A, Barnes J, Leverington M, Ceoloni C, Dodig D (2006) Dissecting a wheat QTL for yield present in a range of environments: from the QTL to candidate genes. Journal of Experimental Botany 57 (11):2627-2637

Quincke MC, Peterson CJ, Zemetra RS, Hansen JL, Chen J, Riera-Lizarazu O, Mundt CC (2011) Quantitative trait loci analysis for resistance to Cephalosporium stripe, a vascular wilt disease of wheat. Theoretical and applied genetics 122 (7):1339-1349

Rajaram S, Van Ginkel M, Fischer R CIMMYT's wheat breeding mega-environments (ME). In: Proceedings of the 8th International wheat genetic symposium, 1993.

Reynolds M, Balota M, Delgado M, Amani I, Fischer R (1994) Physiological and morphological traits associated with spring wheat yield under hot, irrigated conditions. Functional Plant Biology 21 (6):717-730

Reynolds M, Foulkes MJ, Slafer GA, Berry P, Parry MAJ, Snape JW, Angus WJ (2009) Raising yield potential in wheat. Journal of Experimental Botany 60 (7):1899-1918. doi:10.1093/jxb/erp016 
Reynolds M, Tuberosa R (2008) Translational research impacting on crop productivity in drought-prone environments. Curr Opin Plant Biol 11 (2):171-179. doi:10.1016/j.pbi.2008.02.005

Rosegrant MW, Cline SA (2003) Global food security: challenges and policies. Science 302 (5652):1917-1919. doi:10.1126/science.1092958

Semagn K, Bjørnstad Å, Skinnes H, Marøy AG, Tarkegne Y, William M (2006) Distribution of DArT, AFLP, and SSR markers in a genetic linkage map of a doubled-haploid hexaploid wheat population. Genome 49 (5):545-555

Sukumaran S, Dreisigacker S, Lopes M, Chavez P, Reynolds MP (2015) Genome-wide association study for grain yield and related traits in an elite spring wheat population grown in temperate irrigated environments. Theoretical and Applied Genetics 128 (2):353-363

Sukumaran S, Ellis MH, Lopes MS, Pinto S, Bonnett D, Dreisigacker S, Mullan D, Reynolds MP (2013) Wheat mapping populations available at CIMMYT for yield potential research. Wheat Yield Consortium 782013

Sukumaran S, Lopes M, Dreisigacker S, Reynolds M (2018a) Genetic analysis of multi-environmental spring wheat trials identifies genomic regions for locus-specific trade-offs for grain weight and grain number. Theoretical and Applied Genetics 131 (4):985-998. doi:10.1007/s00122-017-3037-7

Sukumaran S, Reynolds MP, Sansaloni C (2018b) Genome-wide association analyses identify QTL hotspots for yield and component traits in durum wheat grown under yield potential, drought, and heat stress environments. Frontiers in plant science 9:81

Tahmasebi S, Heidari B, Pakniyat H, McIntyre CL (2016) Mapping QTLs associated with agronomic and physiological traits under terminal drought and heat stress conditions in wheat (Triticum aestivum L.). Genome 60 (1):26-45

Trethowan RM, Mujeeb-Kazi A (2008) Novel Germplasm Resources for Improving Environmental Stress Tolerance of Hexaploid Wheat. Crop Science 48:1255-1265. doi:10.2135/cropsci2007.08.0477

Varshney RK, Mahendar T, Aggarwal RK, Börner A (2007) Genic molecular markers in plants: development and applications. In: Genomics-assisted crop improvement. Springer, pp 13-29

Yan L, Fu D, Li C, Blechl A, Tranquilli G, Bonafede M, Sanchez A, Valarik M, Yasuda S, Dubcovsky J (2006) The wheat and barley vernalization gene VRN3 is an orthologue of FT. Proceedings of the National Academy of Sciences 103 (51):19581-19586 
459 Yano M, Sasaki T (1997) Genetic and molecular dissection of quantitative traits in rice. In: Sasaki T, Moore G (eds) Oryza: From Molecule to Plant. Springer Netherlands, Dordrecht, pp 145-153. doi:10.1007/978-94-011-

461 5794-0_14

462 Yoshida T, Nishida H, Zhu J, Nitcher R, Distelfeld A, Akashi Y, Kato K, Dubcovsky J (2010) Vrn-D4 is a

463 vernalization gene located on the centromeric region of chromosome 5D in hexaploid wheat. Theoretical

464 and Applied Genetics 120 (3):543-552

465 


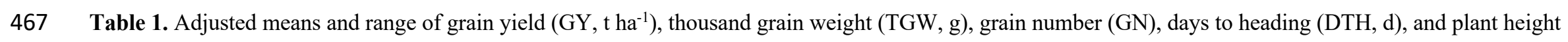

468 (PH, cm) collected on the Seri/Babax RIL population comprising 156 entries in 16 environments from five countries (Egypt, India, Iran, Mexico, and Sudan)

469 during 2004-2005, 2005-2006, and 2008-2009 growing seasons.

\begin{tabular}{|c|c|c|c|c|c|c|c|}
\hline \multirow{2}{*}{ Abbreviations } & \multirow{2}{*}{ Country \& Location } & \multirow{2}{*}{ Year } & \multicolumn{5}{|c|}{ Mean (Range) } \\
\hline & & & GY $\left(\mathrm{t} \mathrm{ha}^{-1}\right)$ & TGW (g) & GN & DTH (d) & PH (cm) \\
\hline EgySha09 & Egypt Shandaweel & 2008-09 & $7.5(6.6-8.3)$ & $45.4(42.9-48.4)$ & $16808(15026-18674)$ & $94(87-102)$ & $108(97-119)$ \\
\hline EgySoh09 & Egypt Sohag & 2008-09 & $7.5(4.9-9.7)$ & $45.4(36.1-54.8)$ & $16697(10754-23453)$ & $94(87-103)$ & $108(94-122)$ \\
\hline IndKar09 & India Karnal & 2008-09 & $4.1(2.3-5.9)$ & $35.1(26-47)$ & $11697(6570-17688)$ & $93(86-102)$ & $100(88-109)$ \\
\hline IndLud09 & India Ludhiana & 2008-09 & $6.6(2.4-10.4)$ & $35.8(29.7-44.3)$ & $18558(5945-29194)$ & $91(85-103)$ & $99(78-111)$ \\
\hline IraDar09 & Iran Darab & 2008-09 & $4.5(2.5-5.9)$ & $34.6(15-79.8)$ & $13229(6551-29540)$ & $112(109-114)$ & - \\
\hline MexObrD05 & Mexico Obregon_Drought & 2004-05 & $3.6(2.8-4.2)$ & $35.2(29.8-42.8)$ & $10268(9018-11363)$ & - & - \\
\hline MexObrD06 & Mexico Obregon_Drought & $2005-06$ & $3.2(2.3-4.0)$ & $34(24.8-43.7)$ & $3405(2463-4556)$ & - & - \\
\hline MexObrD09 & Mexico Obregon_Drought & 2008-09 & $3.8(2.4-5.1)$ & $36.8(31.7-44.1)$ & $10457(5820-14396)$ & $72(67-75)$ & $96(87-103)$ \\
\hline MexObrH05 & Mexico Obregon_Heat & 2005 & $1.8(1.0-2.8)$ & $33.3(28.1-38)$ & $5530(2872-9027)$ & - & - \\
\hline MexObrH06 & Mexico Obregon_Heat & 2006 & $1.2(0.9-1.5)$ & $28.9(23.9-35.2)$ & $11220(7969-14200)$ & - & - \\
\hline MexObrH09 & Mexico Obregon_Heat & 2009 & $3.5(1.8-4.4)$ & $29.2(24.2-41.6)$ & $12019(6712-15035)$ & $53(49-57)$ & $78(71-86)$ \\
\hline MexObrHD09 & Mexico Obregon_Heat + Drought & 2009 & $2.7(1.5-3.6)$ & $26.6(20.2-34.6)$ & $10061(6024-13990)$ & $53(48-57)$ & $71(63-82)$ \\
\hline MexObrYP06 & Mexico Obregon_Yield potential & $2005-06$ & $5.5(4.7-6.0)$ & $43.3(36-50.6)$ & $12778(10855-14976)$ & - & - \\
\hline MexObrYP09 & Mexico Obregon_Yield potential & 2008-09 & $6.6(4.6-8.5)$ & $41(35.2-49.6)$ & $16025(10899-20819)$ & $78(73-81)$ & $102(91-114)$ \\
\hline SudDon09 & Sudan Dongola & 2008-09 & $6.7(4.6-8.8)$ & $42.7(36.5-52.1)$ & $15703(10387-21292)$ & $64(56-73)$ & $88(77-103)$ \\
\hline SudWadM09 & Sudan Wad Medani & 2008-09 & $2.7(1.6-3.9)$ & $36(25.6-45)$ & 7667 (4098-11894) & $55(48-67)$ & $76(46-86)$ \\
\hline
\end{tabular}


471 Table 2. Genetic length, number of markers, average marker interval between two adjacent markers, and number of

472 QTLs identified for (GY, $\left.\mathrm{t} \mathrm{ha}^{-1}\right)$, thousand grain weight (TGW, g), grain number (GN), days to heading (DTH, d), and

473 plant height $(\mathrm{PH}, \mathrm{cm})$ on the 31 linkage groups of the Seri/Babax RIL population linkage map in the present study

474 compared with the previous genetic map (Lopes et al. 2013).

\begin{tabular}{|c|c|c|c|c|c|c|c|c|c|c|c|}
\hline \multicolumn{6}{|c|}{ The updated map } & \multicolumn{6}{|c|}{ The previous map } \\
\hline LG & $\begin{array}{l}\text { Chr/ } \\
\text { Arm }\end{array}$ & $\begin{array}{l}\text { Length } \\
\text { (cM) }\end{array}$ & $\begin{array}{l}\text { Marker } \\
\text { number }\end{array}$ & $\begin{array}{c}\text { Interval } \\
(\mathrm{cM})\end{array}$ & $\begin{array}{l}\text { QTL } \\
\text { num } \\
\text { ber }\end{array}$ & LG & $\begin{array}{l}\text { Chr/ } \\
\text { Arm }\end{array}$ & $\begin{array}{c}\text { Length } \\
\text { (cM) }\end{array}$ & $\begin{array}{l}\text { Marker } \\
\text { number }\end{array}$ & $\begin{array}{c}\text { Interval } \\
(\mathrm{cM})\end{array}$ & $\begin{array}{c}\text { QTL } \\
\text { num } \\
\text { ber }\end{array}$ \\
\hline 1 & $1 \mathrm{~A}$ & 269.3 & 172 & 1.6 & 6 & 1 & $1 \mathrm{~A}$ & 119.9 & 21 & 5.7 & 1 \\
\hline 2 & $1 \mathrm{Ba}$ & 168.7 & 12 & 14.1 & & 2 & $1 \mathrm{~B}$ & 85.0 & 45 & 1.9 & \\
\hline 3 & $1 \mathrm{Bb}$ & 249.8 & 59 & 4.2 & 6 & & & & & & \\
\hline \multirow[t]{2}{*}{4} & $1 \mathrm{D}$ & 350.6 & 84 & 4.2 & 9 & 3 & 1Da & 132.2 & 30 & 4.4 & 1 \\
\hline & & & & & & 4 & $1 \mathrm{Db}$ & 9.1 & 2 & 4.5 & \\
\hline \multirow[t]{4}{*}{5} & $2 \mathrm{~A}$ & 171.8 & 44 & 3.9 & 3 & 5 & $2 \mathrm{Aa}$ & 37.0 & 2 & 18.5 & \\
\hline & & & & & & 6 & $2 \mathrm{Ab}$ & 29.7 & 5 & 5.9 & \\
\hline & & & & & & 7 & $2 \mathrm{Ac}$ & 0.4 & 3 & 0.1 & \\
\hline & & & & & & 8 & $2 \mathrm{Ad}$ & 29.8 & 5 & 6.0 & \\
\hline 6 & $2 \mathrm{~B}$ & 260.7 & 141 & 1.9 & 11 & 9 & $2 \mathrm{~B}$ & 99.0 & 43 & 2.3 & 3 \\
\hline 7 & $2 \mathrm{Da}$ & 100.6 & 28 & 3.6 & & 10 & $2 \mathrm{D}$ & 74.6 & 14 & 5.3 & 1 \\
\hline 8 & $2 \mathrm{Db}$ & 124.6 & 31 & 4.0 & 1 & & & & & & \\
\hline 9 & $3 \mathrm{Aa}$ & 211.2 & 46 & 4.6 & 5 & 11 & $3 \mathrm{Aa}$ & 49.9 & 15 & 3.3 & 1 \\
\hline 10 & $3 \mathrm{Ab}$ & 7.2 & 4 & 1.8 & & 12 & $3 \mathrm{Ab}$ & 13.6 & 9 & 1.5 & \\
\hline 11 & $3 \mathrm{Ba}$ & 52.4 & 14 & 3.7 & & 13 & $3 \mathrm{~B}$ & 142.4 & 37 & 3.8 & \\
\hline 12 & $3 \mathrm{Bb}$ & 314.6 & 94 & 3.4 & 8 & & & & & & \\
\hline 13 & $3 \mathrm{D}$ & 178.7 & 11 & 16.2 & 1 & & & & & & \\
\hline 14 & $4 \mathrm{~A}$ & 352.5 & 125 & 2.8 & 23 & 14 & $4 \mathrm{~A}$ & 110.9 & 43 & 2.6 & 5 \\
\hline 15 & $4 B$ & 201.4 & 91 & 2.2 & 16 & 15 & $4 B$ & 70.1 & 18 & 3.9 & 3 \\
\hline 16 & $4 \mathrm{Da}$ & 43.2 & 6 & 7.2 & 1 & 16 & $4 \mathrm{D}$ & 12.3 & 4 & 3.1 & 1 \\
\hline 17 & $4 \mathrm{Db}$ & 132.0 & 20 & 6.6 & 2 & & & & & & \\
\hline 18 & $5 \mathrm{~A}$ & 295.9 & 129 & 2.3 & 7 & 17 & $5 \mathrm{~A}$ & 76.0 & 22 & 3.5 & 2 \\
\hline 19 & $5 \mathrm{~B}$ & 171.8 & 80 & 2.2 & 1 & 18 & $5 B$ & 14.5 & 17 & 0.9 & 1 \\
\hline 20 & $5 \mathrm{Da}$ & 139.9 & 20 & 7.0 & 5 & 19 & $5 \mathrm{Da}$ & 25.5 & 2 & 12.7 & 1 \\
\hline 21 & $5 \mathrm{Db}$ & 26.9 & 14 & 1.9 & & 20 & $5 \mathrm{Db}$ & 13.0 & 3 & 4.3 & 1 \\
\hline \multirow[t]{2}{*}{22} & $6 \mathrm{~A}$ & 351.6 & 109 & 3.2 & 5 & 21 & $6 \mathrm{Aa}$ & 76.2 & 25 & 3.0 & 2 \\
\hline & & & & & & 22 & $6 \mathrm{Ab}$ & 44.6 & 11 & 4.1 & \\
\hline 23 & $6 \mathrm{~B}$ & 299.9 & 114 & 2.6 & 14 & 23 & $6 \mathrm{~B}$ & 90.3 & 38 & 2.4 & 2 \\
\hline 24 & $6 \mathrm{Da}$ & 157.6 & 42 & 3.8 & 1 & 24 & $6 \mathrm{Da}$ & 41.4 & 4 & 10.4 & 2 \\
\hline 25 & $6 \mathrm{Db}$ & 110.2 & 20 & 5.5 & 2 & 25 & $6 \mathrm{Db}$ & 12.3 & 4 & 3.1 & \\
\hline 26 & $7 \mathrm{~A}$ & 300.1 & 139 & 2.2 & 5 & 26 & $7 \mathrm{~A}$ & 115.2 & 35 & 3.3 & \\
\hline 27 & $7 \mathrm{Ba}$ & 173.0 & 28 & 6.2 & 12 & & & & & & \\
\hline 28 & $7 \mathrm{Bb}$ & 69.7 & 15 & 4.7 & & 27 & $7 \mathrm{~B}$ & 15.6 & 6 & 2.6 & \\
\hline 29 & 7Da & 166.7 & 30 & 5.6 & 22 & 28 & 7Da & 19.0 & 6 & 3.2 & \\
\hline 30 & $7 \mathrm{Db}$ & 119.4 & 21 & 5.7 & & 29 & $7 \mathrm{Db}$ & 52.6 & 6 & 8.8 & 4 \\
\hline 31 & 7Dc & 4.7 & 5 & 0.9 & & & & & & & \\
\hline Total & & 5576.5 & 1748 & 3.2 & 166 & & & 1612 & 475 & 3.4 & 31 \\
\hline
\end{tabular}




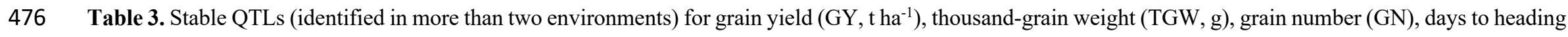

477 (DTH, d), and plant height (PH, cm) in the Seri/Babax RIL population comprising 156 entries. PVE: phenotypic variance explained by QTL.

\begin{tabular}{|c|c|c|c|c|c|c|c|c|c|}
\hline Trait & $\begin{array}{l}\mathbf{L} \\
\mathbf{G}\end{array}$ & $\begin{array}{c}\text { Ch } \\
\mathbf{r}\end{array}$ & $\begin{array}{c}\text { Peak } \\
\text { position } \\
(\mathbf{c M}) \\
\end{array}$ & $\begin{array}{l}\text { Marker interval } \\
\text { (cM) }\end{array}$ & Left marker & Right marker & LOD & $\begin{array}{l}\text { PVE } \\
(\%)\end{array}$ & $\begin{array}{c}\text { Favorabl } \\
\text { e } \\
\text { parent } \\
\end{array}$ \\
\hline \multirow[t]{7}{*}{ GY } & 9 & $3 \mathrm{Aa}$ & 130 & $127-137$ & $a c a-c t a-13$ & 1089533 & 3.1 & 5.4 & Seri \\
\hline & 12 & $3 \mathrm{Bb}$ & 230 & $219-235$ & $w P t-1804$ & gwm301e & 6.5 & 10.7 & Babax \\
\hline & 14 & $4 \mathrm{~A}$ & 268 & $265-269$ & $w m c 048 d$ & act-cag-3 & 10 & 16.6 & Babax \\
\hline & 14 & $4 \mathrm{~A}$ & 284 & $273-293$ & $g U a 44$ & 1089414 & 6.3 & 14.8 & Babax \\
\hline & 14 & $4 \mathrm{~A}$ & 308 & $307-311$ & $w m c 048 c$ & Ra_c7973_1185 & 23.7 & 21.3 & Babax \\
\hline & 23 & $6 \mathrm{~B}$ & 206 & $203-209$ & agc-cta-4 & $\overline{a g g}-\operatorname{ctg}-8$ & 5.4 & 8.4 & Seri \\
\hline & 29 & $7 \mathrm{Da}$ & 124 & $123-125$ & D_contig12156_209 & wsnp_Ex_c4637_8299644 & 6.2 & 10.5 & Seri \\
\hline \multirow[t]{6}{*}{$\begin{array}{l}\text { TG } \\
\mathrm{W}\end{array}$} & 6 & $2 \mathrm{~B}$ & 44 & $37-47$ & $w P t-7320$ & $a c c-c t c-2$ & 4.7 & 9 & Babax \\
\hline & 12 & $3 \mathrm{Bb}$ & 44 & $43-53$ & $\operatorname{barc} 147$ & barc087 & 4.1 & 8.1 & Babax \\
\hline & 22 & $6 \mathrm{~A}$ & 218 & $217-219$ & wsnp_Ku_c26784_3674771 & 998518 & 2.9 & 6.2 & Babax \\
\hline & 27 & $7 \mathrm{Ba}$ & 28 & $23-33$ & $w s n p \_E x \_c 11658 \_1877308$ & wsnp_JD_c1285_1848292 & 3.5 & 9.6 & Babax \\
\hline & 29 & $7 \mathrm{Da}$ & 114 & $99-123$ & Excalibur_c22419_460 & 1068196 & 7.7 & 20.1 & Seri \\
\hline & 29 & 7Da & 124 & $123-125$ & D_contiḡ12156_209 & wsnp_Ex_c4637_8299644 & 7.1 & 11.5 & Seri \\
\hline \multirow[t]{3}{*}{ GN } & 3 & $1 \mathrm{Bb}$ & 80 & $71-83$ & $a c t-c t c-7$ & $\overline{a a c}-\operatorname{ctg}-\overline{4}$ & 8 & 13.9 & Babax \\
\hline & 14 & $4 \mathrm{~A}$ & 308 & $307-311$ & 1072050 & Ra_c7973_1185 & 5.8 & 15.3 & Babax \\
\hline & 23 & $6 \mathrm{~B}$ & 214 & $209-225$ & $w P t-4924$ & $\overline{b a r c 0} \overline{17} 8$ & 4.1 & 6.9 & Seri \\
\hline \multirow[t]{8}{*}{ DTH } & 5 & $2 \mathrm{~A}$ & 160 & $153-167$ & RFL_Contig5277_480 & $c f d 0050$ & 4.2 & 4.1 & Babax \\
\hline & 15 & $4 \mathrm{~B}$ & 70 & $69-71$ & Tdurum_contig4755̄2_957 & Excalibur_c65023_62 & 2.7 & 4.9 & Seri \\
\hline & 15 & $4 \mathrm{~B}$ & 186 & $183-187$ & gwm006a & $a a c-c t c-9$ & 5.6 & 8.9 & Seri \\
\hline & 20 & $5 \mathrm{Da}$ & 38 & $27-43$ & Kukri_c444_833 & Excalibur_c11929_1019 & 7.8 & 9.4 & Babax \\
\hline & 23 & $6 \mathrm{~B}$ & 206 & 201-209 & $\operatorname{agc}-\operatorname{cta}-\overline{4}$ & $a \overline{a c}-c t c-3$ & 7.2 & 6.8 & Babax \\
\hline & 27 & $7 \mathrm{Ba}$ & 20 & $17-25$ & IACX198 & $w s n p \_E x \_c 11658 \_1877308$ & 14.1 & 15 & Seri \\
\hline & 29 & 7Da & 112 & $107-117$ & Excalibur_c22419_460 & 1068196 & 7.6 & 15.2 & Babax \\
\hline & 29 & 7Da & 124 & $117-125$ & Excalibur_c22419_460 & wsnp_Ex_c4637_8299644 & 14.4 & 16 & Babax \\
\hline \multirow[t]{3}{*}{$\mathrm{PH}$} & 6 & $2 \mathrm{~B}$ & 84 & $81-87$ & $a c \bar{a}-\operatorname{ctg}-1$ & $\bar{w} P t-5680$ & 4.2 & 8.6 & Babax \\
\hline & 9 & $3 \mathrm{Aa}$ & 166 & $161-181$ & 1086318 & RAC875_c21944_117 & 3 & 7.6-7.8 & Seri \\
\hline & 14 & $4 \mathrm{~A}$ & 268 & $265-277$ & $w m c 048 d$ & $w m c 048 c$ & $\begin{array}{l}3.4- \\
4.8 \\
\end{array}$ & $8.1-13$ & Seri \\
\hline
\end{tabular}


$15 \quad 4 \mathrm{~B}$

192

191-195

aag-cta-5 
Figure 1. Phenotyping the Seri/Babax RIL population comprising 156 entries was conducted in (a) several environments, (b) clusters of high-yielding and low-yielding environments, and (c) and phenotypic correlations of grain yield between the environments.

Figure 2. Genetic map and marker distribution of the Seri/Babax RIL population on 31 linkage groups.

Figure 3. Updated linkage map of the Seri/Babax population (left) projected to the physical map of IWGSC RefSeq genome v1.0 (right) showing a good collinearity between the genetic map and the physical map.

Figure 4. A stable QTL on chromosome $4 \mathrm{~A}$ detected for grain yield (GY, $\left.\mathrm{t} \mathrm{ha}^{-1}\right)$ and grain number (GN) under yield potential (YP), drought (D), and head plus drought (HD) environments in Obregon, Mexico during 2004-2005, 2005-2006, and 2008-2009 growing seasons.

Figure 5. Venn diagram illustrating the common and specific QTLs for high-yielding and low-yielding environment clusters of the Seri/Babax RIL population. Subscript numbers indicate the centi morgan (cM) position on the linkage map, followed by traits. GY: grain yield $\left(\mathrm{t} \mathrm{ha}^{-1}\right)$; TGW: thousand-grain weight (g); GN: grain number; DTH: days to heading (d); PH: plant height (cm).

Figure 6. Venn diagram illustrating the common genomic regions for grain yield ( $\left.\mathrm{GY}, \mathrm{t} \mathrm{ha}^{-1}\right)$, thousand-grain weight (TGW, g), and grain number (GN), days to heading (DTH, d) and plant height (PH, cm). Subscript numbers indicate the centi morgan (cM) position on the linkage map. For the GY, TGW, and GN QTLs independent from DTH and/or $\mathrm{PH}$, the red up arrows indicates the favorable allele contributed by the same parent, and the black down arrows indicates the favorable allele contributed by different parents.

497 Supplementary Figure 1. Phenotypic correlations among grain yield (GY, $\left.\mathrm{t} \mathrm{ha}^{-1}\right)$, thousand grain weight (TGW, g), grain number $(\mathrm{GN})$, days to heading (DTH, d), and plant height $(\mathrm{PH}, \mathrm{cm})$ of the Seri/Babax RIL population 499 grown in different environments.

500 Supplementary Figure 2. Distribution of markers between two consecutive loci along genetic distance over all 501 chromosomes.

502 Supplementary Figure 3. An updated genetic map of Seri/Babax RIL population with QTLs identified for grain 503 yield (GY, $\left.\mathrm{t} \mathrm{ha}^{-1}\right)$, thousand-grain weight (TGW, g), grain number (GN), days to heading (DTH, d), and plant height 
$504(\mathrm{PH}, \mathrm{cm})$ in different environments. Markers in red and green color are distorted markers in favor of Babax and Seri 505 alleles, respectively.

\section{Supplementary Tables}

507

Supplementary Table 1. Phenotypic data including grain yield (GY, $\left.\mathrm{t} \mathrm{ha}^{-1}\right)$, thousand-grain weight (TGW, g), grain number (GN), days to heading (DTH, d), and plant height $(\mathrm{PH}, \mathrm{cm})$ of the Seri/Babax RIL population grown in 16 environments from five countries.

511 Supplementary Table 2. Linkage map information of the Seri/Babax population. Seri is coded as "0", Babax is coded 512 as "2", and missing data is coded as "-1".

513 Supplementary Table 3. Linkage map information of the Seri/Babax population using 90K SNPs. Seri is coded as 514 "0", Babax is coded as "2", and missing data is coded as "-1".

515 Supplementary Table 4. QTLs detected for grain yield (GY, $\left.\mathrm{t} \mathrm{ha}^{-1}\right)$, thousand-grain weight (TGW, g), grain number 516 (GN), days to heading (DTH, d), and plant height $(\mathrm{PH}, \mathrm{cm})$ of the the Seri/Babax RIL population in 16 individual 517 environments.

518 Supplementary Table 5. QTLs detected for grain yield (GY, $\left.\mathrm{t} \mathrm{ha}^{-1}\right)$, thousand-grain weight (TGW, g), grain number 519 (GN), days to heading (DTH, d), and plant height (PH, cm) of the Seri/Babax RIL population in high-yielding and 520 low-yielding clusters.

521 Supplementary Table 6. Comparison of QTLs detected in the present study with the previous studies using the 522 Seri/Babax RIL population. 